\title{
General Psychiatry Determination of venlafaxine and its active metabolite O-desmethylvenlafaxine in human plasma by HPLC fluorescence
}

\author{
Shujuan Shen, Chen Zhang, Yemeng Mao
}

To cite: Shen S, Zhang C, Mao Y. Determination of venlafaxine and its active metabolite 0-desmethylvenlafaxine in human plasma by HPLC fluorescence. General Psychiatry 2018;31:e000010. doi:10.1136/ gpsych-2018-000010

Received 11 April 2018 Revised 06 June 2018 Accepted 03 July 2018

\section{Check for updates}

(c) Author(s) (or their employer(s)) 2018. Re-use permitted under CC BY-NC. No commercial re-use. See rights and permissions. Published by BMJ.

Shanghai Mental Health Center, Shanghai Jiao Tong University, Shanghai, China

Correspondence to

Yemeng Mao;

mao_yemeng@163.com

\section{ABSTRACT}

Background Therapeutic drug monitoring guides clinical individualised medication by measuring plasma concentration, which could improve the curative effect, avoid drug overdose and reduce the incidence of adverse reactions. At present, there are few reports on the clinical detection of venlafaxine and its active metabolite 0 -desmethylvenlafaxine. In this paper, the detection method of venlafaxine and 0-desmethylvenlafaxine in blood plasma was established, which provides an effective and convenient means for guiding clinical application of medication.

Aim To establish a method for determination of venlafaxine and its active metabolite 0 -desmethylvenlafaxine in human plasma by highperformance liquid chromatography with fluorescence detection.

Methods Chromatographic separation was achieved on an Agilent Eclipse XDB-C18 Column $(4.6 \times 150 \mathrm{~mm}, 5 \mu \mathrm{m})$ with water containing sodium dihydrogen phosphate $(0.05$ $\mathrm{mol} / \mathrm{L})$ and acetonitrile $(72: 28)$ as the mobile phases. The following parameters were employed: flow rate $0.5 \mathrm{~mL}$ min, column temperature $30^{\circ} \mathrm{C}$, fluorescence excitation wavelength $276 \mathrm{~nm}$ and emission wavelength $598 \mathrm{~nm}$.

Results The method showed good linearity in the concentration range $10-1000 \mathrm{ng} / \mathrm{mL}$. The regression equation for venlafaxine was $\mathrm{R}=0.0054 \mathrm{C}+0.0264$, $r^{2}=0.99991$. The regression equation for 0 -desmethylvenlafaxine was $\mathrm{R}=0.0034 \mathrm{C}+0.0272$, $r^{2}=0.99969$. The intraday and interday precisions (relative SD) were less than $10 \%$, and the quantitative limit was 10 $\mathrm{ng} / \mathrm{mL}$.

Conclusion We established a sensitive, specific and simple method for the detection of venlafaxine and 0-desmethylvenlafaxine. This method fully meets the needs of clinical trials of venlafaxine and the requirements of relevant guidelines. It provided a reference for the clinical detection of venlafaxine and 0 -desmethylvenlafaxine plasma concentrations and pharmacokinetic study.

\section{INTRODUCTION}

Venlafaxine is the first drug of serotonin (5-HT) and norepinephrine reuptake dual inhibitors, and is also known as a novel antidepressant with unique chemical structure and neuropharmacological activities that differed from other antidepressants. ${ }^{1}$ Venlafaxine is mainly metabolised by liver cytochrome $\mathrm{P} 450$ enzymes in vivo, producing the main active metabolite O-desmethylvenlafaxine (ODV) and two other lower active secondary metabolites N-desmethylvenlafaxine and N,O-desmethylvenlafaxine. The generation of O-desmethylvenlafaxine from venlafaxine is the most important metabolic pathway. In recent years, the research referring to the plasma concentration of new antidepressants has attracted the attention of scholars from all over the world, but there are few reports about venlafaxine and ODV. Some studies only investigated the effects of age, sex and smoking on venlafaxine plasma concentration. According to the research findings at that time, AGNP consensus guidelines for therapeutic drug monitoring in psychiatry (2011 edition) ${ }^{2}$ suggested that the medication reference concentration of venlafaxine ranged from 100 to $400 \mathrm{ng} / \mathrm{mL}$, and the alert concentration level was $800 \mathrm{ng}$ / $\mathrm{mL}$. If the patient is intolerant, or shows toxic reactions with the plasma concentration of venlafaxine reaching or exceeding the alert concentration, the dosages should be appropriately reduced; if the patient has no obvious adverse reactions, and drug reduction may bring the risk of worsening the disease, the dosages can be maintained. In the Therapeutic Drug Monitoring (TDM) Consensus Guide (2011 edition), the TDM necessity recommendation rating was redefined as four levels: level 1, strongly recommended; level 2, recommended; level 3, useful; level 4, may be useful. The TDM classification of venlafaxine is listed as level 2, recommendation level. It is recommended to further expand the TDM optimisation treatment for venlafaxine.

In this paper, the detection method of venlafaxine and its active metabolite 
Literature investigation and methods sc reening

Establishment of the method: column, a Agilent Eclipse XDB-C18 (4.6×150

$\mathrm{mm}, 5 \mu \mathrm{m}$ ); mobile phase, water containing sodium dihyd rogen phosphate

$(0.05 \mathrm{~mol} / \mathrm{L})$ and acetonitrile (72:28); flow rate, $0.5 \mathrm{~mL} / \mathrm{min}$; column

temperature, $30^{\circ} \mathrm{C}$; fluorescence excitation waveleng th, $276 \mathrm{~nm}$; and

emission wavelength, $598 \mathrm{~nm}$

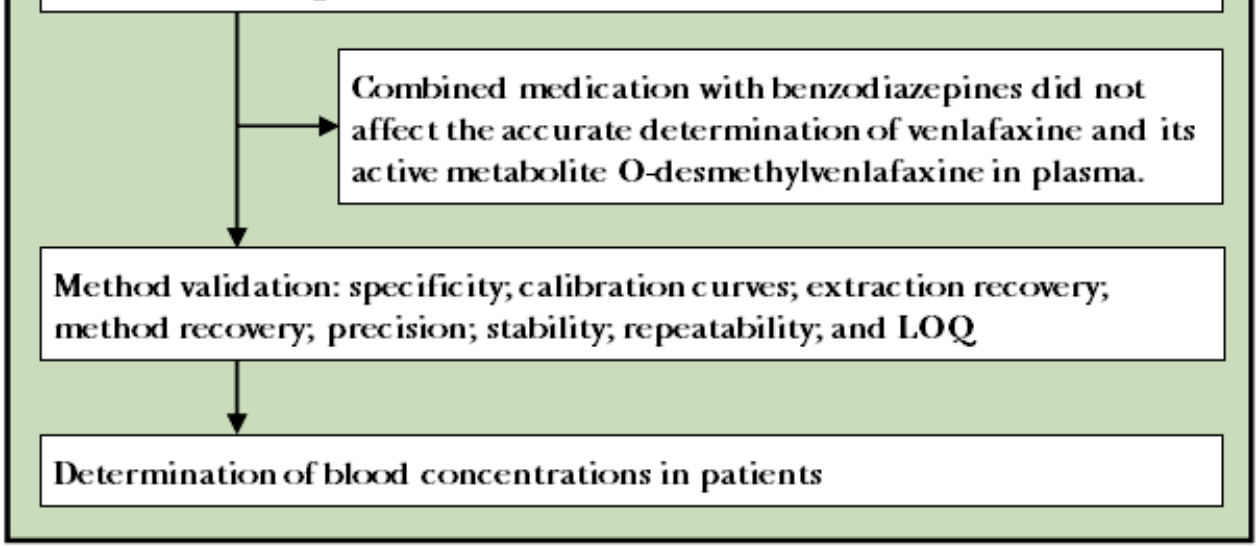

Figure 1 Flowchart of the study.

O-desmethylvenlafaxine in plasma was studied. By optimising chromatographic conditions and sample pretreatment method, we established a high-performance liquid chromatography (HPLC) method with mexiletine as an internal standard. This method showed high specificity, sensitivity, accuracy, resolution and reproducibility, and provided a new detection method for clinical research of venlafaxine.

\section{METHODS}

\section{Instruments and reagents}

The analysis was performed on an Agilent 1200 HPLC. Other instruments involved were a vortex mixer, electronic balance, centrifuge (Xiangyi H2050R) and nitrogen blowing apparatus. The following reagents were used: acetonitrile (Thermo Fisher, HPLC grade), sodium dihydrogen phosphate (Sigma-Aldrich, spectrum pure), triethylamine (Thermo Fisher), phosphoric acid (National Pharmaceutical Group, analytical grade), venlafaxine standard (China Food and Drug Testing Institute), mexiletine hydrochloride (China Food and Drug Testing Institute) and O-desmethylvenlafaxine (Belling, Shanghai). Blank plasma samples were collected from our group's healthy members (figure 1).

\section{Chromatographic conditions}

Chromatographic separation was achieved on an Agilent Eclipse XDB-C18 $(4.6 \times 150 \mathrm{~mm}, 5 \mu \mathrm{m})$ at $30^{\circ} \mathrm{C}$. The mobile phase consisted of water containing sodium dihydrogen phosphate $(0.05 \mathrm{~mol} / \mathrm{L})$ and acetonitrile
(72:28). The flow rate was set at $0.5 \mathrm{~mL} / \mathrm{min}$. The fluorescence excitation wavelength was $276 \mathrm{~nm}$, and the emission wavelength was $598 \mathrm{~nm}$. The injection volume was $10 \mu \mathrm{L}$.

\section{Preparation of solutions}

To prepare 0.05 (mol/L) sodium dihydrogen phosphate solution, $\mathrm{NaH}_{2} \mathrm{PO}_{4} \cdot \mathrm{H}_{2} \mathrm{O}(3.44893 \mathrm{~g})$ was dissolved in water $(500 \mathrm{~mL})$ plus triethylamine $(10 \mu \mathrm{L})$, and phosphoric acid was used to adjust $\mathrm{pH}$ to 2.90. The standard stock solution of venlafaxine hydrochloride was prepared as follows: venlafaxine hydrochloride (2.33 $\mathrm{mg}$ ) was accurately weighed into a $10 \mathrm{~mL}$ brown volumetric flask, dissolved with $50 \%$ methanol-water to achieve the stock solution $(206 \mu \mathrm{g} / \mathrm{mL})$. The standard stock solution of O-desmethylvenlafaxine $(212 \mu \mathrm{g} / \mathrm{mL})$ and the stock solution of internal standard (mexiletine, $193.6 \mu \mathrm{g} / \mathrm{mL}$ ) were prepared as described above. The stock solution of internal standard was diluted to internal standard solution $(50 \mu \mathrm{g} / \mathrm{mL})$ with $50 \%$ methanolwater before use. The standard solutions containing venlafaxine and O-desmethylvenlafaxine were prepared as follows: appropriate volume of standard stock solutions of venlafaxine and O-desmethylvenlafaxine was mixed, then diluted with $50 \%$ methanol-water to prepare the standard solutions containing venlafaxine and O-desmethylvenlafaxine with concentrations of 25 , $18.725,12.5,5,2.5,1.25,0.5$ and $0.25 \mu \mathrm{g} / \mathrm{mL}$, respectively. All the stock and standard solutions were stored at $4^{\circ} \mathrm{C}$ before use. 

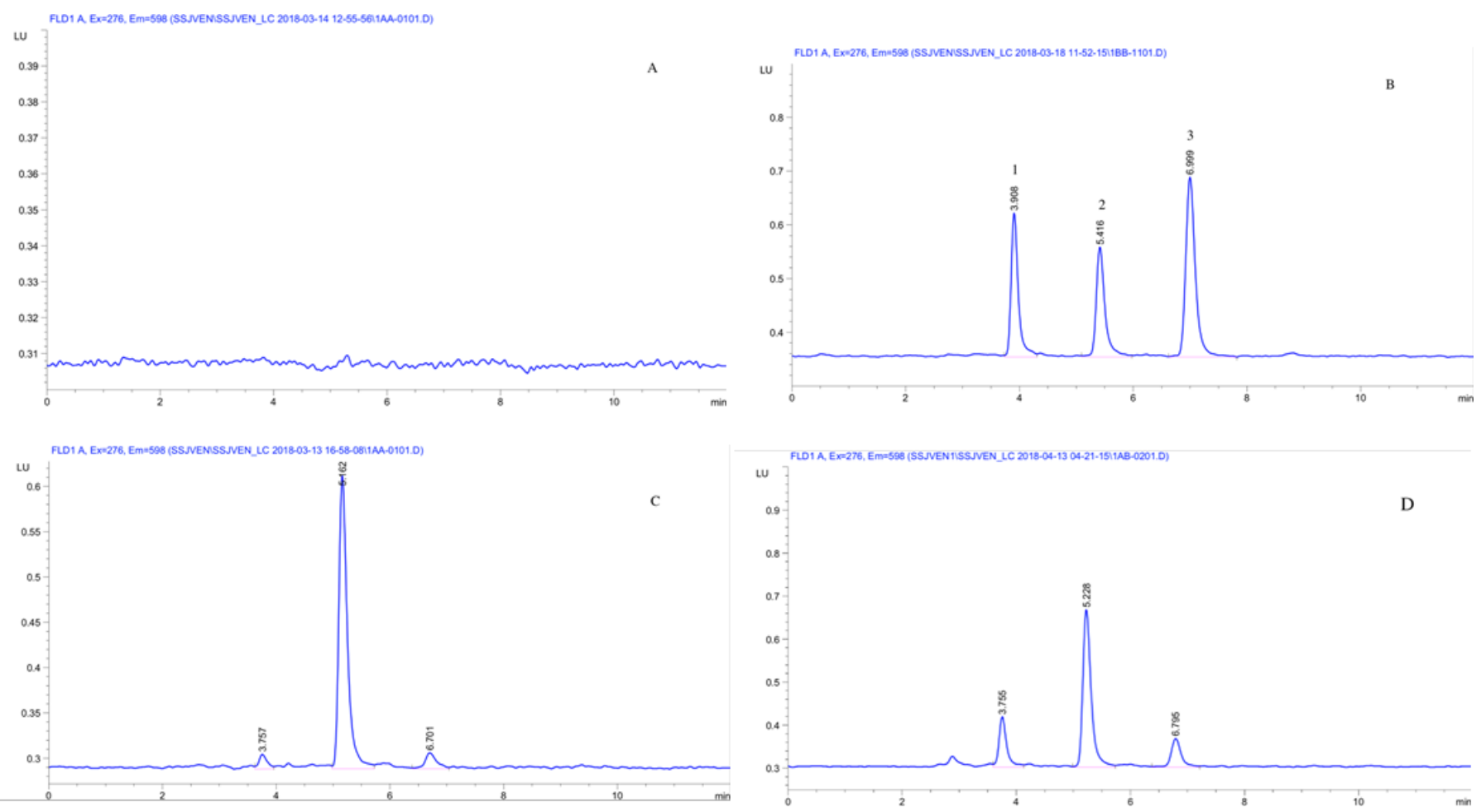

Figure 2 High-performance liquid chromatography chromatograms of venlafaxine and O-desmethylvenlafaxine. (A) blank plasma; (B) blank plasma spiked with O-desmethylvenlafaxine (1), mexiletine (2) and venlafaxine (3); (C) the limit of quantitation $(10 \mathrm{ng} / \mathrm{mL})$ of venlafaxine and O-desmethylvenlafaxine; (D) the chromatogram of plasma from patient.

\section{Treatment of plasma samples}

The plasma sample $(500 \mu \mathrm{L})$ and $30 \mu \mathrm{L}$ internal standard solution (mexiletine, $50 \mu \mathrm{g} / \mathrm{mL}$ ) were added to a 5 $\mathrm{mL}$ stoppered centrifuge tube. The solution was mixed by vortex-mixing at $1500 \mathrm{rpm}$ for 3 min, extracted with ether $(3 \mathrm{~mL})$ by vortex-mixing at $1500 \mathrm{rpm}$ for $3 \mathrm{~min}$. After centrifugation at $3000 \mathrm{rpm}$ for $15 \mathrm{~min}$, the supernatant was transferred to a new tube and evaporated to dryness under a stream of nitrogen at $30^{\circ} \mathrm{C}$. The residue was re-dissolved in mobile phase $(100 \mu \mathrm{L})$ by vortexmixing for $10 \mathrm{~s}$, and $10 \mu \mathrm{L}$ supernatant was injected into HPLC.

\section{Specificity}

The specificity of the method was determined by injecting the plasma samples prepared from blank plasma and blank plasma spiked with internal standard, venlafaxine and O-desmethylvenlafaxine. The samples were processed by following the same operations in the Treatment of plasma samples section. The effects of blank plasma on the determination of drugs were observed by chromatogram. Then, the plasma chromatograms of the patients taking venlafaxine were examined.

Many patients in our hospital took venlafaxine in combination with benzodiazepines. Accordingly, in this study, we investigated the effects of alprazolam, clonazepam and lorazepam on the determination of venlafaxine. About $2 \mathrm{mg}$ of alprazolam, clonazepam and lorazepam were respectively weighed and dissolved in
$10 \mathrm{~mL}$ volumetric flasks with $50 \%$ methanol-water. The samples were directly injected into HPLC.

\section{Drawing of calibration curves}

The plasma samples containing venlafaxine and O-desmethylvenlafaxine were prepared by spiking each of above standard solutions $(20 \mu \mathrm{L})$, blank plasma $(500$ $\mu \mathrm{L})$ and internal standard $(30 \mu \mathrm{L})$ at final concentrations of $1000,750,500,200,100,50,20$ and $10 \mathrm{ng} /$ $\mathrm{mL}$. According to the operations in the Preparation of solutions section, the plasma samples were processed and then injected into HPLC. The chromatograms were recorded. The calibration curves were performed using a weighted $\left(1 / \mathrm{c}^{2}\right)$ least-squares linear regression method by measuring the peak-area ratio of the analytes to the internal standard. The abscissa $\mathrm{X}$ represented the plasma concentration of analytes and ordinate $\mathrm{Y}$ represented the peak-area ratio of the analytes to the internal standard.

\section{Extraction recovery}

The extraction recoveries of QC (quality control) samples were investigated at three different concentrations. According to the operations in the Preparation of solutions section, the QC samples, containing venlafaxine and O-desmethylvenlafaxine at concentrations of 20,200 and $750 \mathrm{ng} / \mathrm{mL}$, were prepared by spiking standard solutions and blank plasma $(500 \mu \mathrm{L})$. After an injection into HPLC, the peak-area of venlafaxine and O-desmethylvenlafaxine was determined and recorded 

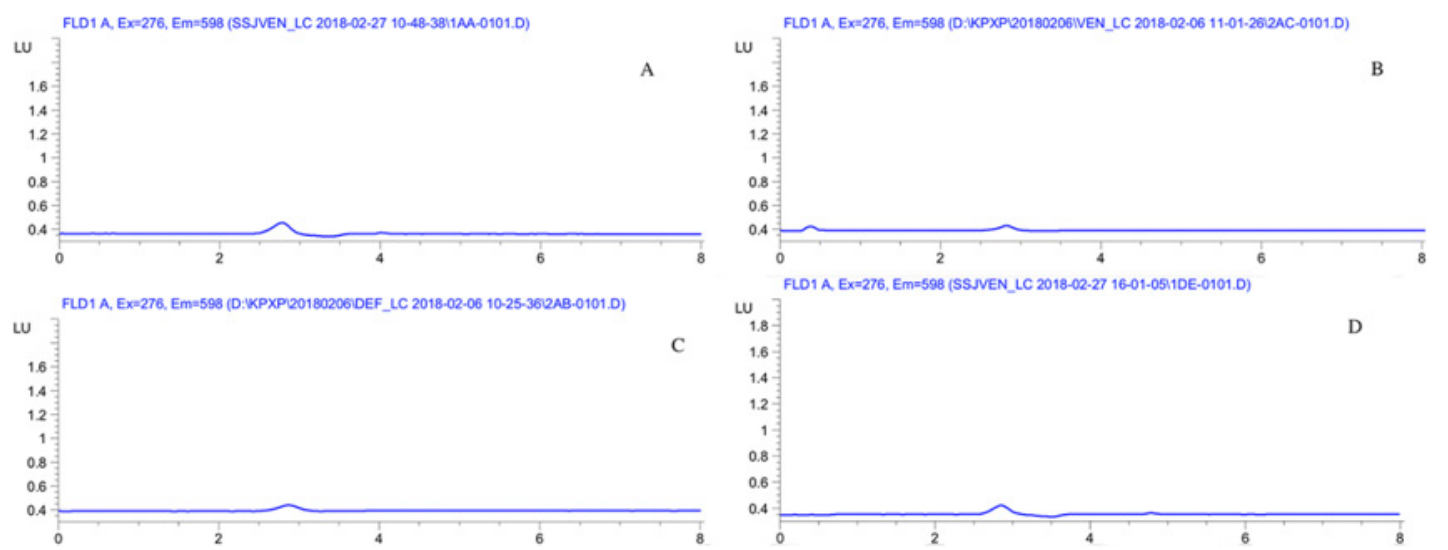

Figure 3 High-performance liquid chromatography chromatograms of combined medication. (A) Chromatogram of alprazolam; (B) chromatogram of clonazepine; (C) chromatogram of lorazepam; (D) chromatogram of methanol.

as A1. Each sample at different concentrations was parallelly measured five times. Also, an appropriate amount of the standard solution containing venlafaxine and O-desmethylvenlafaxine was blown dry under a nitrogen stream at $40^{\circ} \mathrm{C}$, reconstituted by adding 100 $\mu \mathrm{L}$ mobile phase, then injected into HPLC. The peakarea ratio of the analytes to the internal standard was recorded as A2. The extraction recoveries were calculated by the values of A1/A2.

\section{Method recovery}

The QC samples containing venlafaxine and O-desmethylvenlafaxine at three different concentrations of 20, 200 and $750 \mathrm{ng} / \mathrm{mL}$ were prepared according to the methods of 'drawing of standard curves'. The postoperations were processed as described in the Preparation of solutions section. Each of the QC samples was parallelly measured five times; the peak areas of the analytes and the internal standard were recorded as $\mathrm{As}$ and $\mathrm{Ai}$, respectively. The analytes' concentrations were calculated by substituting $\mathrm{R}=\mathrm{As} / \mathrm{Ai}$ into the standard curve equation, and then the recoveries were determined by the ratio of the measured concentrations to the prepared concentrations.

\section{Precision}

The QC samples were prepared as described above. Each of the QC samples was parallelly determined five times. Intraday precision was examined on the same day; the interday precision was determined on three consecutive days. The concentrations of the QC samples were calculated in accordance with the calibration curves. The relative SDs (RSDs) of intraday and interday precision were calculated on the basis of the menstruated results of the QC samples.

\section{Stability and repeatability}

The QC samples containing venlafaxine and O-desmethylvenlafaxine at three concentrations of 20, 200 and 750 $\mathrm{ng} / \mathrm{mL}(\mathrm{n}=5)$ were prepared as described in the Preparation of solutions section and stored at room temperature. The samples were determined after being placed
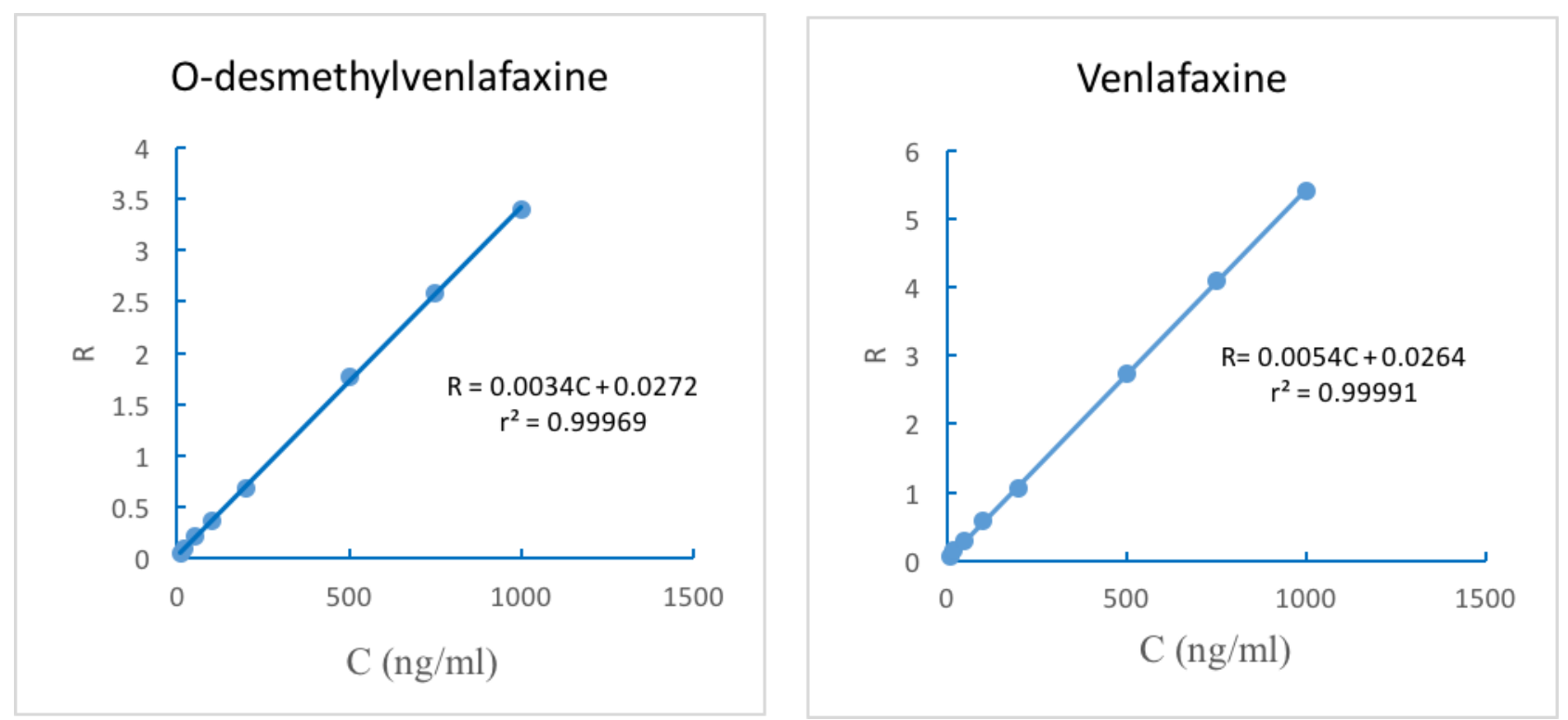

Figure 4 Calibration curves of venlafaxine and O-desmethylvenlafaxine in plasma. 
for 0,24 and 48 hours. The QC samples were stored at $-20^{\circ} \mathrm{C}$, determined at 0,45 and 90 days. The chromatograms were recorded to investigate the stability of the stock solution.

\section{Limit of quantitation (LOQ)}

The plasma samples spiked with different concentrations of venlafaxine and O-desmethylvenlafaxine were prepared without internal standard and processed according to the pretreatment of blood samples. The limit of quantitation was defined by the signal-to-noise ratio $(\mathrm{S} / \mathrm{N}=10)$.

\section{RESULTS}

\section{Specificity}

As shown in figure 2, under the above chromatographic conditions, the retention times of the three analytes were $3.908 \mathrm{~min}$ for O-desmethylvenlafaxine, $5.416 \mathrm{~min}$ for internal standard and about $6.999 \mathrm{~min}$ for venlafaxine, respectively. Under the conditions of fluorescence detection, no endogenous interference was observed at the retention times of all the three analytes that were well separated with the resolution $(R)>1.5$.

\section{Interference of combined medication}

When the concentrations of alprazolam, clonazepam and lorazepam were about $200 \mu \mathrm{g} / \mathrm{mL}$ that was much greater than the therapeutic window concentrations of alprazolam $(5-50 \mathrm{ng} / \mathrm{mL})$, clonazepam $(4-80 \mathrm{ng} / \mathrm{mL})$ and lorazepam $(10-15 \mathrm{ng} / \mathrm{mL}),{ }^{3}$ no obvious fluorescence peaks were found despite a small solvent peak at $2.8 \mathrm{~min}$, as shown in figure 3 . The results indicated that combined medication with benzodiazepines did not affect the accurate determination of venlafaxine and its active metabolite O-desmethylvenlafaxine.

\section{Calibration curves}

The regression equations of venlafaxine and O-desmethylvenlafaxine, as shown in figure 4 , are $\mathrm{R}=0.0054 \mathrm{C}+0.0264$ $\left(r^{2}=0.99991\right)$ and $\mathrm{R}=0.0034 \mathrm{C}+0.0272\left(\mathrm{r}^{2}=0.99969\right)$, respectively. The calibration curves for venlafaxine and O-desmethylvenlafaxine were linear over the concentration range of $10-1000 \mathrm{ng} / \mathrm{mL}$. The results showed that each analyte had favourable linearity.

\section{Extraction recovery and method recovery}

The results of extraction recovery and method recovery are shown in table 1 . The extraction recoveries of venlafaxine and O-desmethylvenlafaxine from plasma were more than $70 \%$ and $80 \%$ (both RSD less than $10 \%$ ), respectively. The method recoveries of venlafaxine and O-desmethylvenlafaxine were between $90 \%$ and $110 \%$ with RSD below $10 \%$, which met the requirements for the analysis of biological samples.

\section{Intraday and interday precision}

The intraday and interday precision were determined and shown in table 2. The intraday and interday precision of venlafaxine and O-desmethylvenlafaxine were both below $10 \%$, indicating that the method had a favourable precision.

\section{Stability and repeatability}

The samples were tested after being placed for 0,24 and 48 hours. As shown in table 3, venlafaxine and O-desmethylvenlafaxine were stable with RSD below $10 \%$, indicating the stability of this method is acceptable. A good repeatability of the method was also observed. The stock solutions stored at $-20^{\circ} \mathrm{C}$ were determined at different times $(0,45$ and 90 days). The two analytes were stable, as shown in table 4 , which met the requirements for the analytical method.

\section{Limit of quantitation}

According to $\mathrm{S} / \mathrm{N}=10$, the $\mathrm{LOQ}$ of venlafaxine and O-desmethylvenlafaxine was $10 \mathrm{ng} / \mathrm{mL}$, as shown in figure 4 .

\section{DISCUSSION}

\section{Main findings}

Venlafaxine has no obvious affinity towards adrenergic, M1 cholinergic and histamine $\mathrm{H} 1$ receptors. As a result, venlafaxine shows few adverse reactions, high safety and rapid onset due to its fast downregulation of beta receptors. Venlafaxine exhibits striking advantages over other antidepressants, acting as a first-line drug for depression. ${ }^{3}$ Currently, there are few reports on the clinical detection of venlafaxine and its active metabolites. A previous study ${ }^{4}$ employed UV detection to determine venlafaxine and O-desmethylvenlafaxine. However, $\mathrm{UV}$ detection is susceptible to endogenous substances,

Table 1 Extraction recovery and method recovery of venlafaxine (VEN) and O-desmethylvenlafaxine (ODV) in plasma

\begin{tabular}{|c|c|c|c|c|c|}
\hline \multirow[b]{2}{*}{ Samples } & \multirow[b]{2}{*}{ Concentration (ng/mL) } & \multicolumn{2}{|c|}{ Extraction recovery $(n=5)$} & \multicolumn{2}{|c|}{ Method recovery $(n=5)$} \\
\hline & & Mean (\%) & RSD (\%) & Mean (\%) & RSD (\%) \\
\hline \multirow[t]{3}{*}{ ODV } & 20 & $78.53(1.26)$ & 1.60 & $101.78(6.43)$ & 6.31 \\
\hline & 200 & $70.70(5.14)$ & 7.27 & $99.38(5.38)$ & 5.42 \\
\hline & 750 & $71.30(4.08)$ & 5.73 & $99.15(4.86)$ & 4.90 \\
\hline \multirow[t]{3}{*}{ VEN } & 20 & $89.36(4.84)$ & 5.42 & $101.78(5.67)$ & 5.57 \\
\hline & 200 & $83.83(6.86)$ & 8.18 & $103.70(6.70)$ & 6.46 \\
\hline & 750 & $84.21(4.08)$ & 6.65 & $102.78(5.73)$ & 5.58 \\
\hline
\end{tabular}

RSD, relative SD. 
Table 2 Intraday and interday precision of venlafaxine (VEN) and O-desmethylvenlafaxine (ODV) in plasma

\begin{tabular}{|c|c|c|c|c|}
\hline Samples & $\begin{array}{l}\text { Spiked concentration } \\
(\mathrm{ng} / \mathrm{mL})\end{array}$ & $\begin{array}{l}\text { Detected concentration } \\
\text { (ng/mL) }\end{array}$ & RSD (intraday n=5) (\%) & RSD (interday n=15) (\%) \\
\hline \multirow[t]{9}{*}{ ODV } & \multirow[t]{3}{*}{20} & $20.20(1.51)$ & 7.49 & \multirow[t]{3}{*}{6.49} \\
\hline & & $19.98(1.20)$ & 6.01 & \\
\hline & & $19.92(1.23)$ & 6.41 & \\
\hline & \multirow[t]{3}{*}{200} & $198.79(5.41)$ & 2.72 & \multirow[t]{3}{*}{4.21} \\
\hline & & $196.36(9.63)$ & 4.91 & \\
\hline & & $198.75(10.76)$ & 5.42 & \\
\hline & \multirow[t]{3}{*}{750} & 752.36 (18.30) & 2.43 & \multirow[t]{3}{*}{4.57} \\
\hline & & $747.74(20.84)$ & 2.79 & \\
\hline & & $761.05(55.84)$ & 7.34 & \\
\hline \multirow[t]{9}{*}{ VEN } & \multirow[t]{3}{*}{20} & $20.74(1.51)$ & 7.29 & \multirow[t]{3}{*}{5.48} \\
\hline & & $20.89(1.01)$ & 6.01 & \\
\hline & & $19.92(0.68)$ & 3.41 & \\
\hline & \multirow[t]{3}{*}{200} & $208.09(5.32)$ & 2.56 & \multirow[t]{3}{*}{4.06} \\
\hline & & $206.75(6.20)$ & 4.91 & \\
\hline & & $207.41(13.41)$ & 6.46 & \\
\hline & \multirow[t]{3}{*}{750} & $762.12(19.02)$ & 2.50 & \multirow[t]{3}{*}{4.86} \\
\hline & & $754.54(17.35)$ & 2.79 & \\
\hline & & 790.78 (56.22) & 7.11 & \\
\hline
\end{tabular}

RSD, relative SD.

Table 3 Stability and repeatability of venlafaxine (VEN) and O-desmethylvenlafaxine (ODV) in plasma

\begin{tabular}{|c|c|c|c|c|c|}
\hline Samples & $\begin{array}{l}\text { Concentration (ng/ } \\
\mathrm{mL})\end{array}$ & Time (h) & $\begin{array}{l}\text { Detected } \\
\text { concentration }(n=5) \\
(\mathrm{ng} / \mathrm{mL})\end{array}$ & RSD (\%) (n=5) & $\operatorname{RSD}(\%)(n=15)$ \\
\hline \multirow[t]{9}{*}{ ODV } & 20 & 0 & $20.36(1.29)$ & 6.31 & 7.20 \\
\hline & & 24 & $18.94(0.69)$ & 3.65 & \\
\hline & & 48 & $20.41(1.82)$ & 8.91 & \\
\hline & 200 & 0 & $198.75(10.76)$ & 5.42 & 5.05 \\
\hline & & 24 & $199.25(13.72)$ & 6.88 & \\
\hline & & 48 & $197.63(6.75)$ & 3.42 & \\
\hline & 750 & 0 & $743.64(36.43)$ & 4.90 & 6.41 \\
\hline & & 24 & $762.61(58.27)$ & 7.64 & \\
\hline & & 48 & 769.73 (55.78) & 7.25 & \\
\hline \multirow[t]{9}{*}{ VEN } & 20 & 0 & $20.35(1.13)$ & 5.57 & 6.25 \\
\hline & & 24 & $21.27(2.12)$ & 9.09 & \\
\hline & & 48 & $21.12(0.68)$ & 3.24 & \\
\hline & 200 & 0 & $207.41(13.4)$ & 6.46 & 5.94 \\
\hline & & 24 & $201.98(11.75)$ & 5.82 & \\
\hline & & 48 & $206.34(13.51)$ & 6.55 & \\
\hline & 750 & 0 & 770.85 (43.01) & 5.58 & 6.01 \\
\hline & & 24 & $778.72(58.27)$ & 6.86 & \\
\hline & & 48 & $798.34(52.21)$ & 6.60 & \\
\hline
\end{tabular}

RSD, relative SD. 
Table 4 Stability of stock solutions

\begin{tabular}{|c|c|c|c|c|c|}
\hline Samples & Concentration (ng/mL) & Time (day) & $\begin{array}{l}\text { Detected concentration }(n=5) \\
(\mathrm{ng} / \mathrm{mL})\end{array}$ & RSD (\%) (n=5) & RSD (\%) (n=15) \\
\hline \multirow[t]{6}{*}{ ODV } & 20 & 0 & $20.36(1.29)$ & 6.31 & 8.07 \\
\hline & & 90 & $19.31(28.31)$ & 1.47 & \\
\hline & 200 & 0 & $198.75(10.76)$ & 5.42 & 6.57 \\
\hline & 750 & 0 & $743.64(36.43)$ & 4.9 & 9.37 \\
\hline & & 45 & $751.00(12.51)$ & 1.67 & \\
\hline & & 90 & 751.77 (20.99) & 2.79 & \\
\hline \multirow[t]{6}{*}{ VEN } & 20 & 0 & $20.35(1.13)$ & 5.57 & 8.58 \\
\hline & & 45 & $203.41(19.17)$ & 9.42 & \\
\hline & & 90 & $206.40(2.62)$ & 1.27 & \\
\hline & 750 & 0 & 770.85 (43.01) & 5.58 & 9.52 \\
\hline & & 45 & $758.00(14.98)$ & 1.98 & \\
\hline & & 90 & 755.67 (25.66) & 3.4 & \\
\hline
\end{tabular}

ODV, O-desmethylvenlafaxine; RSD, relative SD; VEN, venlafaxine.

consequently being interfered with by miscellaneous peaks. Fluorescence detection shows higher detection sensitivity $(31.25 \mu \mathrm{g} / \mathrm{L})$ than UV without interference by endogenous impurities and solvents. Thus, we adopted fluorescence detection to determine venlafaxine and O-desmethylvenlafaxine. By adjusting the flow ratio and $\mathrm{pH}$, venlafaxine, O-desmethylvenlafaxine and mexiletine were well separated with good peak shapes. Furthermore, it was reported ${ }^{5}$ that mass spectrometry (MS) was used to detect the concentrations of venlafaxine and O-desmethylvenlafaxine in canine plasma, but not in human plasma. MS shows similar sensitivity with fluorescence detection; however, the cost is much higher than fluorescence detection with higher requirements for the processing of blood samples. The fluorescence detection method displays high specificity, good peak shape and high resolution without endogenous interference, which could accurately determine the concentration of drugs in the plasma and optimise the extraction processes of blood samples. Hence, it provides a convenient means for monitoring clinical medication.

As the column filled with small particle size fillers is easily blocked by the precipitated proteins from blood samples, liquid-liquid extraction was employed to treat the blood sample in our study. Reports ${ }^{67}$ on the determination methods of venlafaxine blood concentration mostly used hexane-isopropanol and diethyl ether ${ }^{5}$ as extraction solvents. Initially, we used $n$-hexane-isopropanol (98:2) as extraction solvents and found that there was no obvious O-desmethylvenlafaxine peak in the chromatogram, showing that $n$-hexane-isopropanol failed to extract O-desmethylvenlafaxine. In another study, ${ }^{5}$ during the extraction of blood samples with diethyl ether, $50 \mu \mathrm{L}$ acetonitrile-water (40:60) was added. In our experiment, we compared the extraction effects by adding or not adding acetonitrile-water, and found that the addition of acetonitrile-water did not increase the extraction rate. According to the principles of simplicity, speed and efficiency, we only used diethyl ether for the extractions and achieved good results.

The effects of combined medication on the determination of venlafaxine and O-desmethylvenlafaxine in plasma during clinical drug use were not considered in other studies. In our study, we investigated the effects of combined venlafaxine with benzodiazepines in our hospital. It was found that alprazolam, clonazepam and lorazepam showed no obvious fluorescence peaks under the fluorescent conditions, indicating that the combined medication with benzodiazepines did not affect the detection of venlafaxine and O-desmethylvenlafaxine. Researchers have used maprotiline, ${ }^{7}$ chlorpromazine, ${ }^{6}$ risperidone ${ }^{48}$ oxazepam $^{9}$ and fluvoxamine $^{10}$ as the internal standards when measuring the concentration of venlafaxine. These internal standards are generally used in psychiatry and interfered with the detection due to frequently combined medication with venlafaxine. Therefore, we employed a non-psychotic drug, mexiletine, as the internal standard, which reduced the possibility of the combination of the 
Table 5 Plasma concentrations of some patients treated with venlafaxine

\begin{tabular}{llcc}
\hline & \multicolumn{2}{c}{ Plasma concentrations $\mathbf{( n g} / \mathbf{m L})$} & \\
\cline { 2 - 3 } Patient ID & O-Desmethylvenlafaxine & Venlafaxine & Dosage (mg, daily) \\
\hline 1 & 239 & 74 & 75 \\
2 & 68 & 35 & 75 \\
3 & 70 & 24 & 150 \\
\hline 4 & 202 & 42 & 225 \\
\hline 5 & 160 & 80 & 150 \\
\hline
\end{tabular}

internal standard with venlafaxine and improved the accuracy of the detection.

\section{Limitations}

Although the method showed reliable ability to detect venlafaxine and its main active metabolite O-desmethylvenlafaxine, this study did not determine the other two lower active metabolites of venlafaxine.

\section{Implications}

This study established a HPLC fluorescence method to detect the plasma concentrations of venlafaxine and its active metabolite O-desmethylvenlafaxine. The peak shapes were good without interference of endogenous impurity peaks. The method, which met the needs of clinical experiments and the requirements of relevant guidelines, could be used to determine the plasma concentrations of venlafaxine and its active metabolite O-desmethylvenlafaxine. Thus, we established a detection method for clinical individualised medication and provided a theoretical basis for the pharmacokinetic study of venlafaxine in vivo.

We also tested the plasma concentrations of six hospitalised patients treated with venlafaxine sustained-release capsules (Pfizer). The results showed that the peaks were well separated. The data of plasma concentration are shown in table 5, which is consistent with the Arbeitsgemeinschaft für Neuropsychopharmakologie und Pharmakopsychiatrie (AGNP) Psychiatric TDM Consensus Guide (2017 version $)^{11}$ with high accuracy. Moreover, we could estimate the type of metabolic enzymes on the basis of the concentration ratio of metabolite to the original drug. Our study showed positive significance for guiding clinical individualised medication.

Contributors SS was responsible for the experiment implementation and paper writing; CZ provided literature retrieval and guidance on the methods; YM was responsible for the design and coordination of this study.

Funding This work was supported by Key Project of Pharmaceutical Research Fund of Shanghai Jiaotong University School of Medicine (JDYX2017ED003);
Discipline Construction of Clinical Pharmacy in Psychiatry of Shanghai Mental Health Center

Competing interests None declared.

Patient consent Not required.

Provenance and peer review Not commissioned; externally peer reviewed.

Open access This is an open access article distributed in accordance with the Creative Commons Attribution Non Commercial (CC BY-NC 4.0) license, which permits others to distribute, remix, adapt, build upon this work non-commercially, and license their derivative works on different terms, provided the original work is properly cited and the use is non-commercial. See: http://creativecommons.org/ licenses/by-nc/4.0

\section{REFERENCES}

1. Warneck JB, Cheng FH, Barnes MJ, et al. Action of (R)-silavenlafaxine and reboxetine to antagonize cisplatin-induced acute and delayed emesis in the ferret. Toxicol Appl Pharmacol 2008;232:369-75.

2. Hiemke C, Baumann P, Bergemann N, et al. AGNP consensus guidelines for therapeutic drug monitoring in psychiatry: update 2011. Pharmacopsychiatry 2011;44:195-235.

3. Chermá MD, Ahlner J, Bengtsson F, et al. Antidepressant drugs in children and adolescents: analytical and demographic data in a naturalistic, clinical study. J Clin Psychopharmacol 2011;31:98-102

4. Wang Z, Zhu X, Ma R, et al. Simultaneous determination of venlafaxine and $\mathrm{O}$-desmethylvenlafaxine in human blood serum by RP-HPLC. Zhongguo Yao Xue Za Zhi 2011;01:54-7. Chinese.

5. Zhu M. Study on amlodipine and venlafaxine and metabolites by UPLC-MS/MS method. Chinese: Shenyang Pharmaceutical University, 2009

6. Wei S, Wen Y, Dang H, et al. Simultaneous determination of three antidepressants in human plasma by HPLC-fluorescence method. Zhongguo Yao Fang 2009;26:2026-8. Chinese.

7. Meng J, Sun X, Qin X, et al. Determination the human blood concentration of venlafaxine hydrochloride by HPLC fluorescence and human bioequivalence study. Yao Wu Fen Xi Za Zhi 2008;9:1442-5. Chinese.

8. Yang L, Liu T, Liu X. The effect of CYP2D6*10 allele polymorphism on venlafaxine plasma concentration. Central South Pharmacy 2013;01:23-7. Chinese.

9. Liu G, Qiao S, Yu H, et al. Simultaneous determination of nine antidepressant drugs in human plasma by ultra performance liquid chromatography-tandem mass spectrometry. Zhongguo Lin Chuang Yao Li Xue Za Zhi 2016;23:2191-4. Chinese.

10. He J, Zhou Z, Li H. Simultaneous determination of blood concentration of four new anti depressants by HPLC-MS. Yao Wu Fen Xi Za Zhi 2005;12:1428-32.

11. Hiemke C, Bergemann N, Clement HW, et al. Consensus guidelines for therapeutic drug monitoring in neuropsychopharmacology: update 2017. Pharmacopsychiatry 2018;51:9-62. 


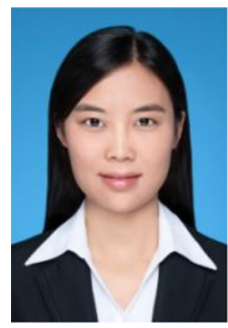

Shujuan SHEN obtained the bachelor degree from Zhenzhou University in 2013, and completed her master's program from Fudan University in 2016, and she has been working in the pharmacy department of Shanghai Mental Health Center since 2016. Currently, she is working as a primary pharmacist. Her research interest is clinical pharmacy.

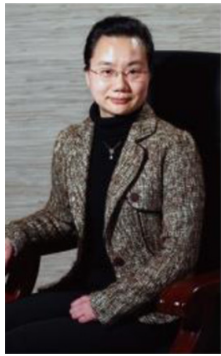

Yemeng MAO graduated from the School of Pharmacy, Shanghai Medical University in 1991 with a Bachelor's Degree and obtained a Master's Degree in Pharmacy from the college of pharmacy of Fudan University in 2008. Since 1991, she has been working in the pharmacy department of the Shanghai Mental Health Center, and now acts as the director of the department of pharmacy with a research interest in clinical pharmacy. 